\title{
Influence of the Preparation Procedure on the Electrochemical Properties of Pani(DMcT-Cu ion)/Carbon Fiber Composites
}

\author{
Sheila C. Canobre, Sonia R. Biaggio*, Romeu C. Rocha-Filho and Nerilso Bocchi \\ Departamento de Química, Universidade Federal de São Carlos, CP 676, 13560-970 São Carlos - SP, Brazil
}

\begin{abstract}
As propriedades eletroquímicas de compósitos do tipo Pani(DMcT-íon Cu)/fibra de carbono, obtidos eletroquimicamente, são analisadas em função tanto do procedimento de preparação como do sal de cobre $\left(\mathrm{CuCl}_{2} \cdot 2 \mathrm{H}_{2} \mathrm{O}\right.$ ou $\left.\mathrm{CuSO}_{4}\right)$ utilizado para a incorporação de íons $\mathrm{Cu}^{2+}$ no compósito. Dois procedimentos foram utilizados: adicionando-se o sal de cobre diretamente ao eletrólito durante a eletropolimerização da polianilina (procedimento A), ou adsorvendo-se os íons cobre juntamente com o DMcT sobre a fibra de carbono antes da eletropolimerização (procedimento B). A estabilidade eletroquímica, as propriedades elétricas e a morfologia desses compósitos foram analisadas, por voltametria cíclica, espectroscopia de impedância eletroquímica e microscopia eletrônica de varredura, respectivamente.
\end{abstract}

The electrochemical properties of Pani(DMcT-Cu ion)/carbon fiber composites, obtained by electrochemical means, are analysed as a function of the preparation procedure and the different copper salts $\left(\mathrm{CuCl}_{2} \cdot 2 \mathrm{H}_{2} \mathrm{O}\right.$ or $\left.\mathrm{CuSO}_{4}\right)$ used as source of $\mathrm{Cu}^{2+}$ ions to be incorporated into the Pani(DMcT)/carbon fiber composite. The composites were prepared according to two procedures: by adding the copper salt directly to the electrolyte during the polyaniline electrosynthesis (procedure A), or by allowing the copper ion to be physically adsorbed onto the carbon fiber prior to the polymer electroformation (procedure B). The electrochemical stability, electrical properties and morphology of the composites were analysed by cyclic voltammetry, electrochemical impedance spectroscopy and scanning electron microscopy, respectively.

Keywords: polyaniline, carbon fiber, DMcT, composites, impedance spectroscopy

\section{Introduction}

In the recent past decades, the demand for rechargeable batteries has exploded due to the enormous increase in the variety and number of portable devices, especially cellular phones. At the same time, the need has increased for batteries that are smaller, lighter, with higher energy density and more environmentally benign. It is expected that this dependence on batteries as energy sources will become even greater in the future due to an increase in the number of miniaturized devices. Therefore development of novel electrode materials is currently demanded so as to increase the energy density of batteries for different applications, including those for electric vehicles and the load leveling of electric power consumption.

Disulfide compounds have been recently proposed as alternative materials for high-energy cathodes in lithium batteries. ${ }^{1-14}$ A series of compounds having - $\mathrm{SH}$ groups are

*e-mail: biaggio@ power.ufscar.br thought to have a significant potential as energy storage materials, whereby energy exchange occurs according to a reversible polymerization-depolymerization process (2 SH $\leftrightarrow \mathrm{S}-\mathrm{S}){ }^{1,2}$ Among these compounds, 2,5-dimercapto1,3,4-thiadiazole (DMcT) was first studied by Visco and co-workers ${ }^{6}$ as an active cathode material for lithium secondary batteries. However, its redox reaction is too slow at room temperature. Thus, to improve the redox dynamics of DMcT at room temperature, polyaniline (Pani) was used to make a composite with it, since this polymer acts as an electrocatalyst for the redox reaction of DMcT. ${ }^{15}$ The PaniDMcT composite cathode material chemically prepared has a theoretical specific capacity of about $224 \mathrm{~mA} \mathrm{~h} \mathrm{~g}^{-1}$ and Oyama and coworkers ${ }^{15}$ reported practical capacities as high as $184 \mathrm{~mA} \mathrm{~h} \mathrm{~g}^{-1}$. These same authors suggested that the excellent molecular-level contact between DMcT and Pani led to extremely efficient catalysis of the redox process of DMcT by Pani.

Recently, metallic copper has been used as a current collector for the composite cathode, resulting in a stable 
charge-discharge cycling performance of over 250 cycles at a $0.82 \mathrm{C}$ rate and an average operating voltage of $3.2 \mathrm{~V}^{16,17}$ It is believed that copper ions dissolve from the current collector to form a complex with DMcT that may accelerate the electron transfer rate within the DMcT-Pani composite film. ${ }^{18}$

Few reports have been published concerning the electrical properties of these chemically-prepared composites and none about their preparation using electrochemical techniques. Thus, in this paper an alternative route for the preparation of Pani(DMcT-Cu ion)/ carbon fiber composites is reported, as well as their characterization by means of cyclic voltammetry and electrochemical impedance spectroscopy. Besides that, the electrochemical and morphological properties of these composites are analysed when different copper salts $\left(\mathrm{CuCl}_{2} \cdot 2 \mathrm{H}_{2} \mathrm{O}\right.$ or $\left.\mathrm{CuSO}_{4}\right)$ are used in the forming electrolyte. The same properties are also analysed as a function of the way the copper ion is incorporated into the composite, according to two procedures: addition of the copper salt directly to the electrolyte during the polyaniline electrosynthesis (procedure A) or physical adsorption of the copper ion onto the carbon fiber prior to the polymer electrosynthesis (procedure B), focusing into obtaining composites of high stability and high capacity for possible application as cathodes in secondary batteries.

\section{Experimental}

The substrates for all the electrosyntheses were carbon fiber pieces (PWB-3, from Stackpole, USA), with a geommetrical area of $2 \mathrm{~cm}^{2}$ exposed to the electrolyte. DMcT was adsorbed onto the fiber pieces by keeping them immersed for $12 \mathrm{~h}$ in acetonitrile (from Mallinckrodt AR HPLC) containing $100 \mathrm{mmol} \mathrm{L}^{-1} \mathrm{DMcT}$ (from Alfa Aesar), according to a procedure described before. ${ }^{19,20}$ Copper ions from different copper salts $\left(\mathrm{CuCl}_{2} .2 \mathrm{H}_{2} \mathrm{O}\right.$ or $\left.\mathrm{CuSO}_{4}\right)$ were incorporated to the Pani(DMcT)/carbon fiber composites according to the two proceduresdescribed below.

\section{Procedure A: copper salts added directly to the electrolyte} for the polyaniline electropolymerization

The polyaniline films were grown onto the carbon fiber/ DMcT electrodes by cyclic voltammetry, between $-0.4 \mathrm{~V}$ and $0.8 \mathrm{~V}$ (vs. SCE) in $0.5 \mathrm{~mol} \mathrm{~L}^{-1} \mathrm{H}_{2} \mathrm{SO}_{4} / 0.1 \mathrm{~mol} \mathrm{~L}^{-1}$ aniline/ $2 \mathrm{mmol} \mathrm{L}^{-1} \mathrm{CuCl}_{2} \cdot 2 \mathrm{H}_{2} \mathrm{O}$ (or $\mathrm{CuSO}_{4}$ ) aqueous solutions, at $2 \mathrm{mV} \mathrm{s}^{-1}$ only for the first cycle. For the other cycles, the growth was continued at $100 \mathrm{mV} \mathrm{s}^{-1}$ between $-0.4 \mathrm{~V}$ and $0.69 \mathrm{~V}$ ( $v s . \mathrm{SCE}$ ) as reported before. ${ }^{19-21}$ The anodic limiting potential was chosen in order to avoid the insulating oxidation state of polyaniline, pernigraniline. ${ }^{22}$ Only when $\mathrm{CuSO}_{4}$ was used, the cathodic potential limit was changed to $-1.0 \mathrm{~V}$ to ensure complete reduction of the polymer.

Procedure B: copper ions physically adsorbed onto the carbon fiber prior to the polyaniline electropolymerization

$\mathrm{DMcT}$ and $\mathrm{Cu}$ ions were adsorbed onto the carbon fiber pieces by keeping them immersed for $12 \mathrm{~h}$ in acetonitrile containing $2 \mathrm{mmol} \mathrm{L}^{-1} \mathrm{CuCl}_{2} \cdot 2 \mathrm{H}_{2} \mathrm{O}$ (or $\mathrm{CuSO}_{4}$ ) and 100 mmol L-1 DMcT. For DMcT concentrations higher than $100 \mathrm{mmol} \mathrm{L}^{-1}$ an undesirable brown precipitate was formed, which is thought to be the dimeric form of the mercaptan. ${ }^{23}$ Polyaniline films were electrochemically grown on this carbon fiber/adsorbed (DMcT-Cu ion) substrate by cyclic voltammetry using the same conditions as in procedure A.

Electrochemical runs were conducted in a conventional three-electrode-Pyrex-glass cell containing Pani(DMcT$\mathrm{Cu}$ ion)/carbon fiber composites as working electrode, a Pt sheet as counter-electrode, and a saturated calomel electrode (SCE) as reference, which were connected to an EG\&G PARC 273A potentiostat/galvanostat. The solutions were kept at room temperature $\left(c a .25^{\circ} \mathrm{C}\right)$ and thoroughly purged with nitrogen before each electrochemical run.

For the electrochemical stability tests, the composites were cycled up to 200 voltammetric cycles in a blank electrolyte $\left(0.5 \mathrm{~mol} \mathrm{~L}^{-1} \mathrm{H}_{2} \mathrm{SO}_{4}\right.$ aqueous solution free of the monomer) and the corresponding electrical charges measured.

The electrical properties of Pani(DMcT-Cu ion)/carbon fiber composites were studied by electrochemical impedance spectroscopy (EIS), using a general purpose electrochemical system and frequency response analyzer (ECOCHEMIE PGSTAT 20). The impedance spectra were obtained potentiostatically at $-0.2 \mathrm{~V}$ and $+0.2 \mathrm{~V} v s$. SCE, always in a $0.5 \mathrm{~mol} \mathrm{~L}^{-1} \mathrm{H}_{2} \mathrm{SO}_{4}$ aqueous solution free of the monomer. The ac signal, with an amplitude of $10 \mathrm{mV}$ (rms), was varied in the $10 \mathrm{mHz}$ to $10 \mathrm{kHz}$ frequency range. The equilibration time was set to $600 \mathrm{~s}$ at each dc potential before the EIS measurements.

The morphological characteristics of the composites were analysed using a 960 DSM Zeiss scanning electron microscope.

\section{Results and Discussion}

The effect of DMcT and copper ion adsorbed onto the carbon fiber substrate

A film of DMcT, physically adsorbed onto the carbon fiber, underwent electropolymerization by continuously 
cycling the electrode between $-0.6 \mathrm{~V}$ to $0.69 \mathrm{~V}$, at $100 \mathrm{mV} \mathrm{s}^{-1}$ in a $0.5 \mathrm{~mol} \mathrm{~L}^{-1} \mathrm{H}_{2} \mathrm{SO}_{4}$ aqueous solution. After 30 cycles, the resulting voltammetric profile of poly(DMcT) is shown in Figure 1 (dashed line). The anodic peak is attributed to the oxidation of DMcT to poly(DMcT), while the cathodic peak corresponds to the respective reduction process. ${ }^{24}$ The large gap between the anodic and cathodic peak potentials $\left(\Delta \mathrm{E}_{\mathrm{p}}\right)$ indicates a slow redox process for DMcT. On the other hand, the continuous line of Figure 1 shows that if copper ions are simultaneously adsorbed onto the carbon fiber, a new oxidation wave (peak I) appears at non-characteristic potentials for the tioamide groups of either protonated or deprotonated DMcT (monomeric and dimeric form, respectively). ${ }^{17,24}$ Therefore, this new peak might be related to the oxidation of a stable DMcT-Cu ion complex. Moreover, peak II corresponds to the oxidation of DMcT to poly(DMcT) shifted to more positive potentials, while the reduction peak potential (peak III) remains unchanged. This can be understood if the oxidation product is the same, either for the free or coordinated tioamide, i.e. the oxidation of the DMcT-Cu(I) complex would yield oxidized DMcT in the oligomeric or polymeric form ${ }^{17}$, which would be reduced at the same potentials. Since the limiting anodic potential was kept the same, the anodic charge for the poly(DMcT) formation (and therefore its reduction) is smaller.

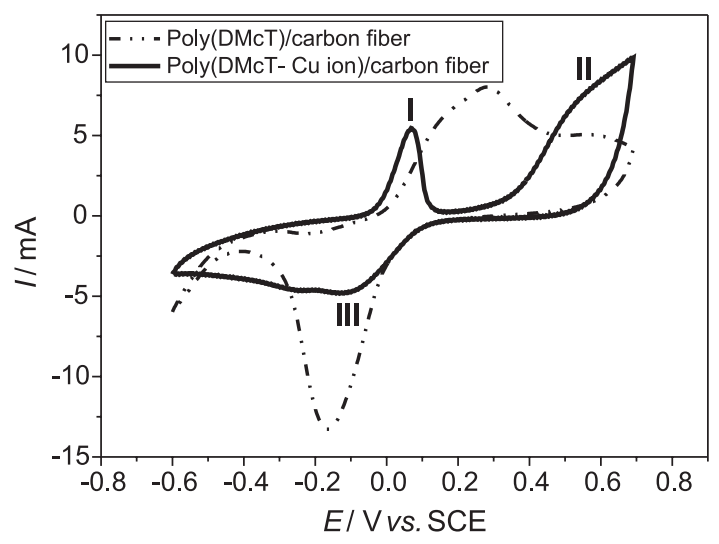

Figure 1. Voltammograms for the adsorbed DMcT/carbon fiber electrodes, after 30 cycles in $0.5 \mathrm{~mol} \mathrm{~L}^{-1} \mathrm{H}_{2} \mathrm{SO}_{4}$ (without and with $\left.2 \mathrm{mmol} \mathrm{L}-1 \mathrm{CuCl}_{2} .2 \mathrm{H}_{2} \mathrm{O}\right)$ at $100 \mathrm{mV} \mathrm{s}^{-1}$.

The influence of the preparation procedure on the composite electrochemical properties

The Pani(DMcT-Cu ion)/carbon fiber composites prepared according to procedure $\mathrm{A}$ (using $\mathrm{CuCl}_{2} \cdot 2 \mathrm{H}_{2} \mathrm{O}$ as copper-ion source) present voltammetric profiles (shown in Figure 2) similar to the ones obtained by procedure B. In both cases the presence of copper ions favours the polyaniline eletropolymerization (anodic charges of $c a$. $730 \mathrm{mC}$ ) when compared to the presence of DMcT alone (anodic charge of $c a .620 \mathrm{mC}$ ). The lower value has been explained as due to the formation of a complex (or aduct) between the thiol and imine groups of DMcT and Pani, respectively, with the remaining poly(DMcT) forming aggregates in polyaniline matrix that would hinder the polymer conductivity. ${ }^{20}$ However, the complex formed between DMcT and the copper ion enhances the electrontransfer reaction of the DMcT redox mechanism mediated by Pani and hinders the non-conductive aggregate formation in the polymer matrix. ${ }^{17}$

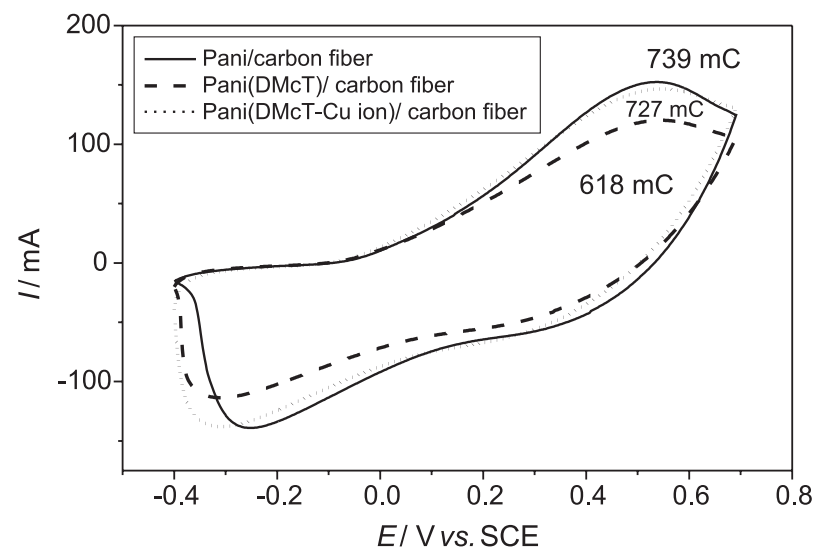

Figure 2. Voltammetric curves for the $300^{\text {th }}$ cycle during the polyaniline formation on different substrates at $100 \mathrm{mV} \mathrm{s}^{-1}$ : just carbon fiber, adsorbed DMcT/carbon fiber, and adsorbed DMcT-Cu ion/carbon fiber (procedure B), in $0.5 \mathrm{~mol} \mathrm{~L}^{-1} \mathrm{H}_{2} \mathrm{SO}_{4}$ / $0.1 \mathrm{~mol} \mathrm{~L}^{-1}$ aniline aqueous solutions (procedure A).

On the other hand, the results of the electrochemical stability tests showed deep differences between the composites prepared by procedures A or B. As depicted in Figure 3, the composites prepared according to procedure A, using $\mathrm{CuCl}_{2}$ as the copper-ion source, showed a sharp loss of charge after 200 voltammetric cycles. This result may be explained by a loss of the composite active mass over the cyclings due to the formation of a less homogeneous and less adherent polymer film around and between the substrate fibers. Besides that, a fraction of DMcT not coordinated with copper ions might form insulating islands of poly(DMcT) and thus decrease the composite electrochemical stability. On its turn, the composite prepared on the simultaneously adsorbed DMcT-Cu ion substrate (procedure B) presented a high electrochemical stability, keeping its initial charge practically constant after 200 cycles (see Figure $3 b$ ).

Figure 4 shows that when $\mathrm{CuSO}_{4}$ is used in the forming electrolyte as the copper-ion source (procedure A), significant changes on the redox potentials occur, 

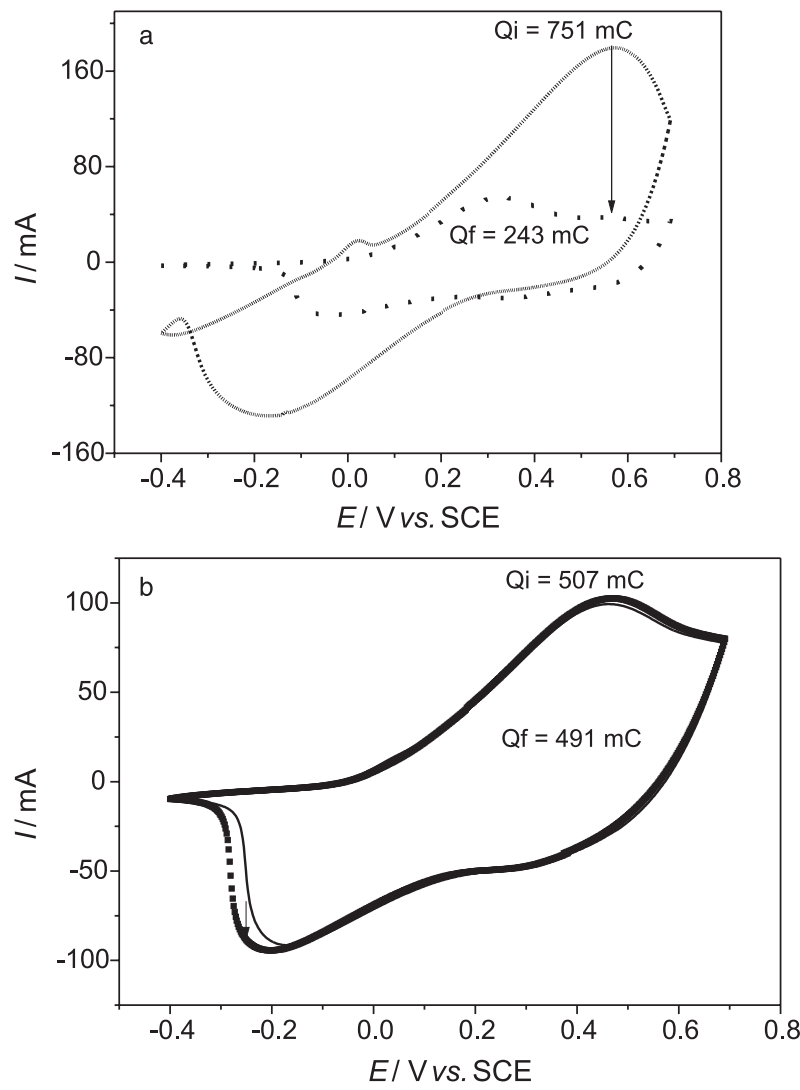

Figure 3. Electrochemical stability tests showing the first and the $200^{\text {th }}$ voltammetric cycles of the Pani(DMcT-Cu ion)/carbon fiber composites prepared with $\mathrm{CuCl}_{2}$ according to procedures $\mathrm{A}$ (a) and $\mathrm{B}$ (b). $\mathrm{v}=100 \mathrm{mV} \mathrm{s}^{-1}$.

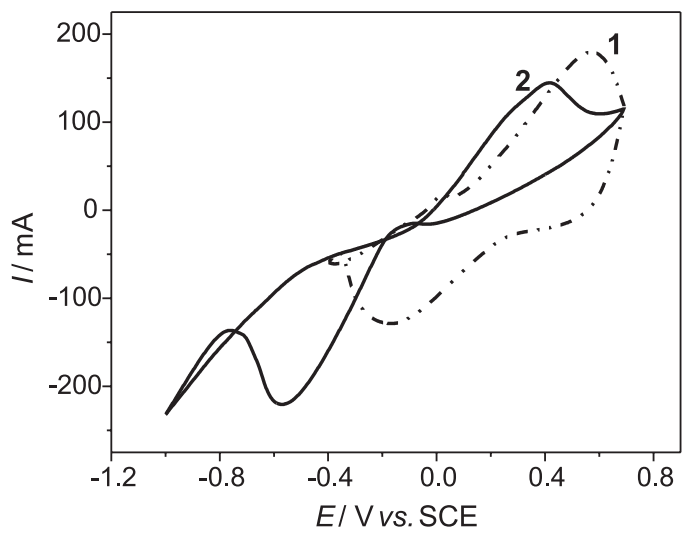

Figure 4. Voltammetric curves for the $300^{\text {th }}$ cycle for the polyaniline formation on adsorbed DMcT/carbon fiber substrates at $100 \mathrm{mV} \mathrm{s}^{-1}$, in $0.5 \mathrm{~mol} \mathrm{~L}^{-1} \mathrm{H}_{2} \mathrm{SO}_{4} / 0.1 \mathrm{~mol} \mathrm{~L}^{-1}$ aniline/ $2 \mathrm{mmol} \mathrm{L}^{-1} \mathrm{CuCl}_{2} .2 \mathrm{H}_{2} \mathrm{O}$ (curve 1) or $\mathrm{CuSO}_{4}$ (curve 2) solutions (procedure A).

corresponding to the insulating leucoemeraldine to conducting emeraldine transition. The change in the redox process is evidenced by the continuous line in Figure 4, showing a higher I $v s$. E slope and a wider $\Delta \mathrm{E}_{\mathrm{p}}$. There are kinetic effects when different counter ions are present in the forming electrolyte, since the polymer oxidation/ reduction processes are dependent on the counter-ion flux to counterbalance the polymeric charge. Nevertheless, similarly to the case of copper-chloride composites, the stability tests for the copper-sulfate composites showed that the ones prepared by procedure A (Figure 5a) have a very low electrochemical stability and the ones prepared by procedure B (Figure 5b) have a high electrochemical stability. For the latter, the initial electrical charge remained unchanged (about $500 \mathrm{mC}$ ) after 200 voltammetric cycles.
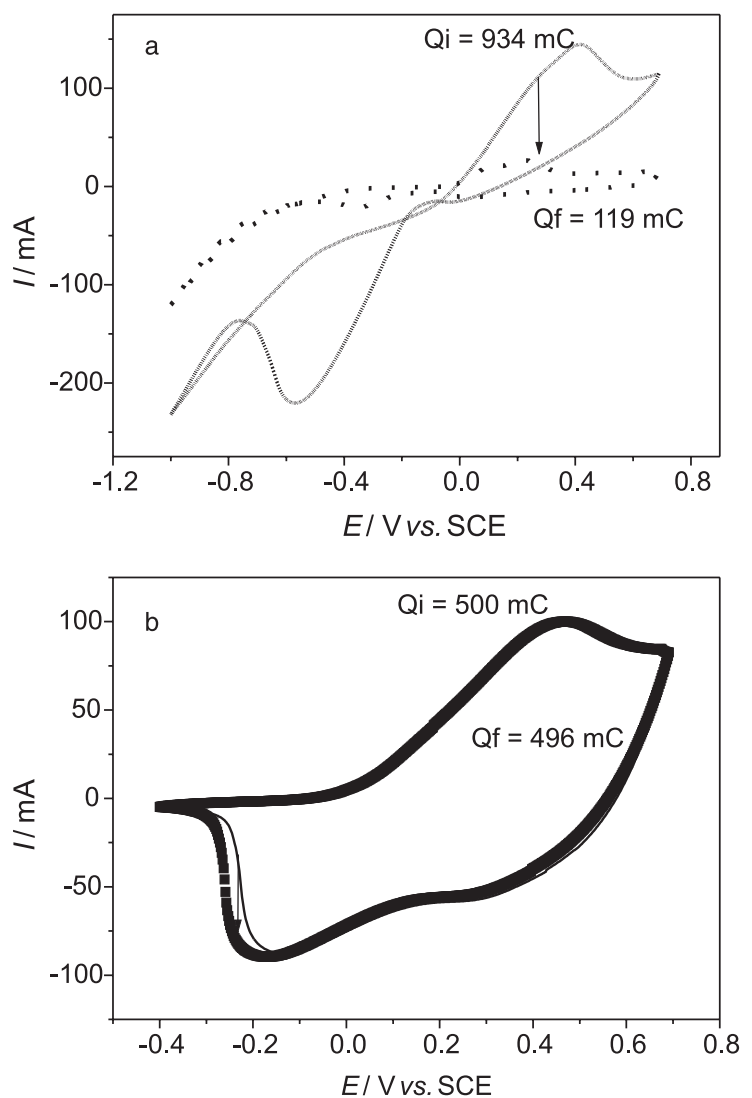

Figure 5. Electrochemical stability tests showing the first and the $200^{\text {th }}$ voltammetric cycles of the Pani(DMcT-Cu ion)/carbon fiber composites prepared with $\mathrm{CuSO}_{4}$ according to procedures $\mathrm{A}$ (a) and B (b). $\mathrm{v}=100 \mathrm{mV} \mathrm{s}^{-1}$.

\section{Electrical properties of the composites}

The electrical properties of the composites electrosynthesized by the different procedures were analysed by EIS. The spectra were accquired at potentiostatic conditions, at dc potentials where Pani is either in the insulating form $(-0.2 \mathrm{~V} v s$. SCE) or in the conducting form $\left(+0.2 \mathrm{~V} v s\right.$. SCE). ${ }^{21,25}$ The analyses of the obtained data were done by using the NLLS partial fit method applied to the different frequency regions.

Complex-plane plots (imaginary impedance Z" vs. real 
impedance $Z^{\prime}$ ) for the composites polarized at $-0.2 \mathrm{~V}$ are presented in Figure 6. All the spectra present a semi-circle, from which the values of the charge transfer resistance $\left(\mathrm{R}_{\mathrm{ct}}\right)$ were obtained. These values can be associated with the redox process within the polymeric film. On the other hand, the complex-plane plots for the composites polarized at $0.2 \mathrm{~V}$, presented in Figure 7, show a capacitive behaviour, i.e. the capacitance values $(\mathrm{C})$ are practically frequency independent, according to $\mathrm{C}=1 /\left(2 \pi \mathrm{fZ}\right.$ "). ${ }^{21,25}$ At this potential, the whole spectrum is shifted to lower impedances and the $\mathrm{R}_{\mathrm{ct}}$ values approach zero, evidencing a sharp

a

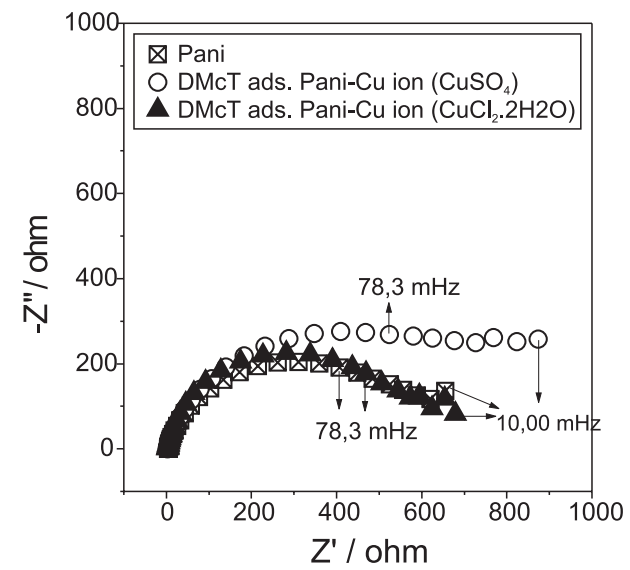

b

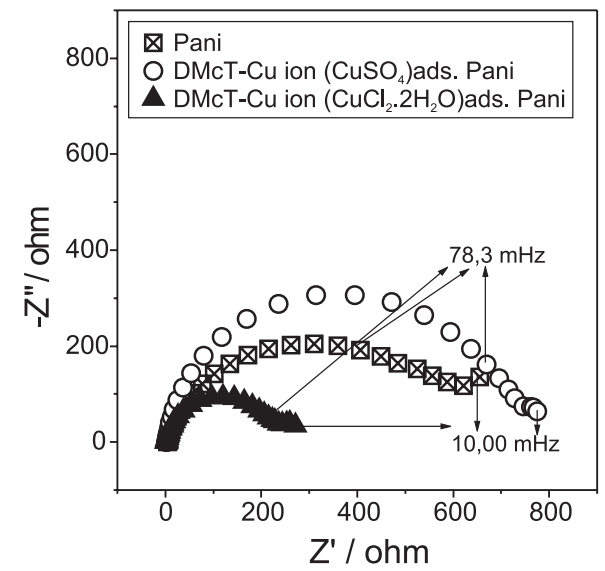

Figure 6. Complex-plane plots for the Pani(DMcT-Cu ion)/carbon fiber composites prepared according to procedures A (a) and B (b), polarized at $-0.2 \mathrm{~V}$ in $0.5 \mathrm{~mol} \mathrm{~L}^{-1} \mathrm{H}_{2} \mathrm{SO}_{4}$ aqueous solutions. transition between the insulating $(-0.2 \mathrm{~V})$ and conducting $(0.2 \mathrm{~V})$ forms of polyaniline.

Typical $\mathrm{R}_{\mathrm{ct}}$ and $\mathrm{C}$ values for the different composites are listed in Table 1 . The $\mathrm{R}_{\mathrm{ct}}$ values are of about $500 \Omega$ to $600 \Omega$, except for the composite prepared by procedure B (using $\mathrm{CuCl}_{2}$ ), which is $250 \Omega$. This lower resistance value might be due to a porous and less thick film, which would facilitate the counter-ion diffusion from the polymeric frame. This assumption is supported by the SEM micrograph for this composite, shown in Figure 8c.

Figure 7 also shows that the composites prepared by

a

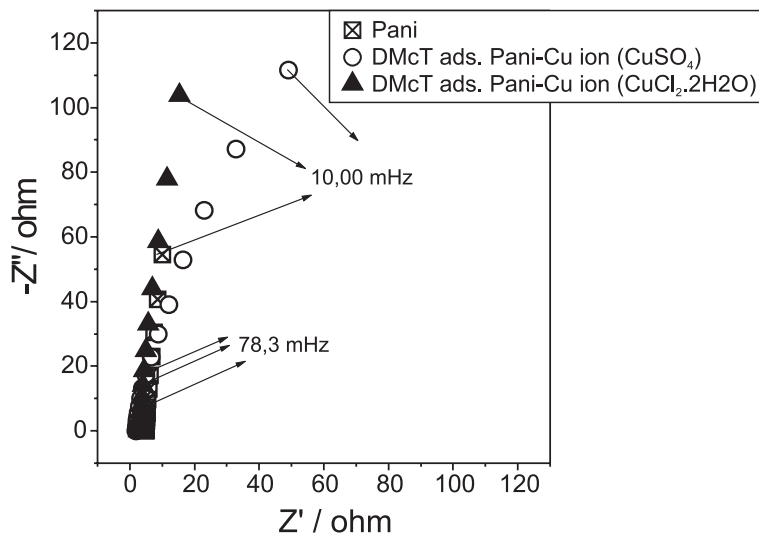

b

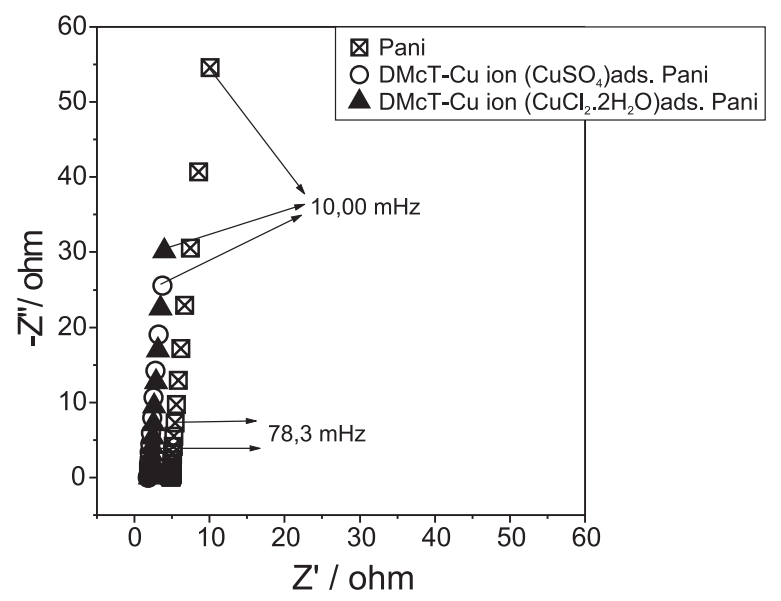

Figure 7. Complex-plane plots for the Pani(DMcT-Cu ion)/carbon fiber composites prepared according to procedures A (a) and B (b), polarized at $0.2 \mathrm{~V}$ in $0.5 \mathrm{~mol} \mathrm{~L}^{-1} \mathrm{H}_{2} \mathrm{SO}_{4}$ aqueous solutions.

Table 1. Charge transfer resistance and capacitance data for the Pani/carbon fiber composite and the Pani(DMcT-Cu ion)/carbon fiber composites obtained by procedures $\mathrm{A}$ and $\mathrm{B}$

\begin{tabular}{lcccccc}
\hline & \multicolumn{2}{c}{ Procedure $\mathrm{A}$} & & \multicolumn{2}{c}{ Procedure B } \\
\cline { 2 - 3 } Electrical Properties & $\begin{array}{c}\text { DMcT ads. } \\
\text { Pani-Cu ion } \\
\left(\mathrm{CuSO}_{4}\right)\end{array}$ & $\begin{array}{c}\text { DMcT ads. } \\
\text { Pani-Cu ion } \\
\left(\mathrm{CuCl}_{2} .2 \mathrm{H}_{2} \mathrm{O}\right)\end{array}$ & & $\begin{array}{c}\text { DMcT-Cu ion } \\
\text { ads.-Pani } \\
\left(\mathrm{CuSO}_{4}\right)\end{array}$ & $\begin{array}{c}\text { DMcT-Cu ion } \\
\text { ads.-Pani } \\
\left(\mathrm{CuCl}_{2} .2 \mathrm{H}_{2} \mathrm{O}\right)\end{array}$ \\
\hline $\mathrm{R}_{\mathrm{ct}} / \Omega(-0.2 \mathrm{~V})$ & 617 & 517 & 673 & 250 & 0.73 \\
$\mathrm{C} / \mathrm{mF}(-0.2 \mathrm{~V})$ & 0.29 & 0.51 & & 0.34 & 465 & 0.45 \\
$\mathrm{C} / \mathrm{mF}(+0.2 \mathrm{~V})$ & 109 & 142 & & 590 & 318 \\
\hline
\end{tabular}


procedure B present the same electrical character, independent of the $\mathrm{Cu}$ salt used for their formation. However, the composites prepared by procedure A (using $\mathrm{CuSO}_{4}$ ) show a higher deviation from the ideal capacitor behaviour, which may be due to more surface heterogeneities as can be seen in the SEM micrograph of Figure $8 b$.

The capacitance values for the composites at $-0.2 \mathrm{~V}$ (reduced Pani) are in the range of $\mu \mathrm{F}$ (see Table 1), characteristic of a metal/electrolyte interface, i.e., the carbon fiber/electrolyte interface. At $+0.2 \mathrm{~V}$ the capacitance values are in the range of $\mathrm{mF}$, consistent with a porous conducting polymer/electrolyte interface. These data are supported by the porous morphology shown for all the composites (see Figure 8), leading to large active areas in contact with the electrolyte and therefore large capacities. The far larger capacitance value $(590 \mathrm{mF})$ obtained for the Pani(DMcT$\mathrm{Cu}$ ion)/carbon fiber prepared according to procedure $\mathrm{B}$ (and using $\mathrm{CuSO}_{4}$ as copper ions source) is consistent with a more porous and homogeneous morphology of a thicker film, as shown in Figure 8d.

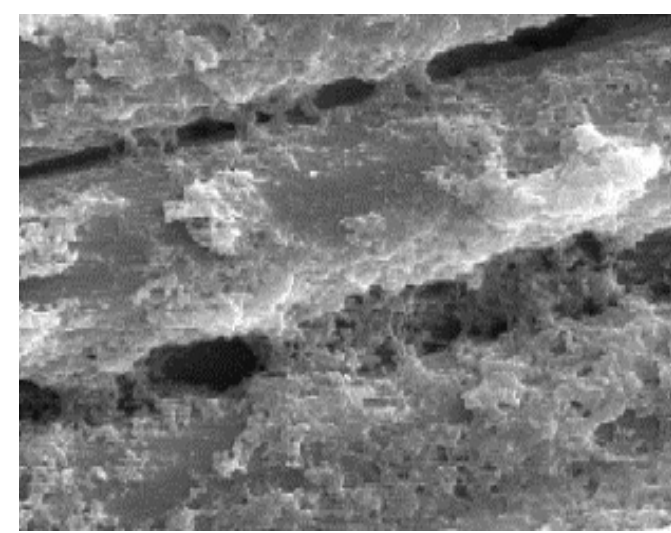

a)

$$
5 \mu \mathrm{m} \longmapsto
$$

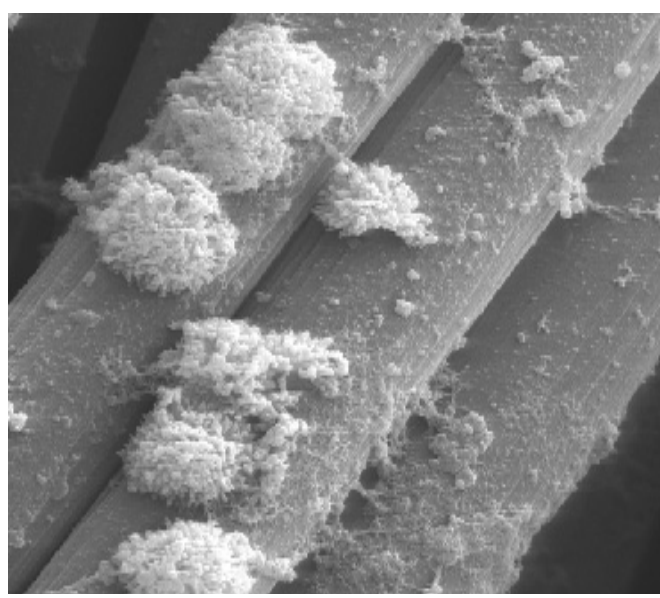

b)

\section{Conclusions}

The obtained results showed that the electrochemical synthesis of Pani(DMcT-Cu ion)/carbon fiber composites can be successfully carried out by two procedures: incorporation of the copper ions from the electrolyte during the electropolymerization (procedure A), or their adsorption onto the carbon fiber(DMcT) substrate (procedure B). Nevertheless, the electrochemical stability, morphology and capacity results showed that the composite prepared according to procedure $\mathrm{B}$ (by $\mathrm{CuSO}_{4}$ adsorption onto the substrate) presents the more promising properties so as to be tested as a cathode in rechargeable batteries.

\section{Acknowledgements}

The authors are grateful to FAPESP, CAPES and CNPq for the scholarships and grants that made this work possible. S.C.C. is grateful to FAPESP for a doctoral scholarship.

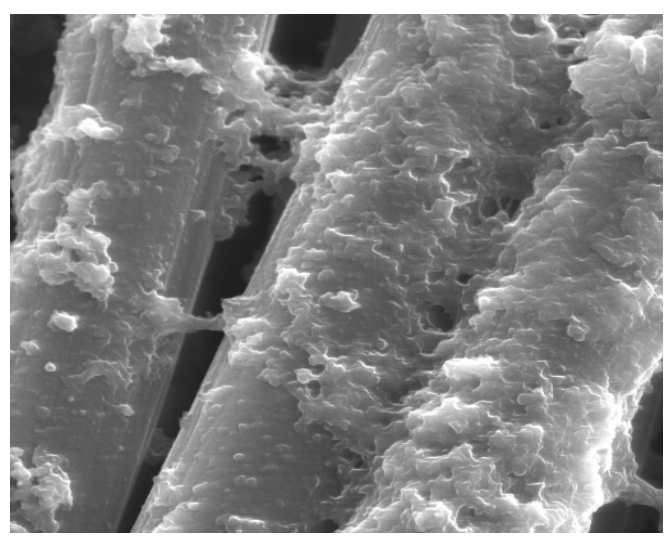

c)

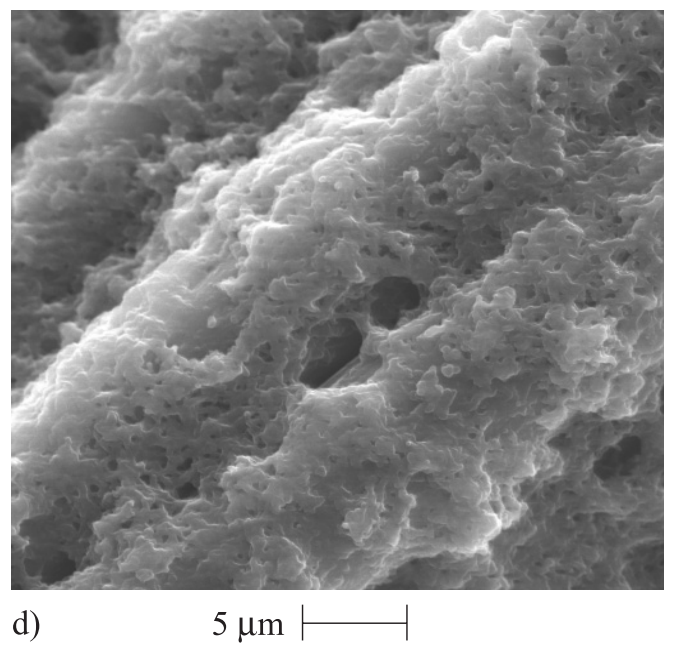

Figure 8. SEM micrographs of the Pani(DMcT-Cu ion)/carbon fiber composites prepared with $\mathrm{CuCl}_{2}$ (procedures A (a) and B (b)), or with $\mathrm{CuSO}_{4}$ (procedures A (c) and B (d)). Magnification of 3000x. 


\section{References}

1. Visco, S.J.; Mailhe, C.C.; De Jonghe, L.C.; Armand, M.B.; Electrochem. Soc. 1989, 136, 661.

2. Visco, S.J.; De Jonghe, L.C.; Mater. Res. Symp. Proc. 1989, 135, 553.

3. Liu, M.; Visco, S.J.; De Jonghe, L.C.; Electrochem. Soc. 1989, 136,2570

4. Visco, S.J.; Liu, M.; De Jonghe, L.C.; Electrochem. Soc. 1990, 137, 1191

5. Liu, M.; Visco, S.J.; De Jonghe, L.C.; Electrochem. Soc. 1990, 137, 750 .

6. Liu, M.; Visco, S.J.; De Jonghe, L.C.; Electrochem. Soc. 1991, 138, 1891.

7. Liu, M.; Visco, S.J.; De Jonghe, L.C.; Electrochem. Soc. 1991, 138, 1896.

8. Doeff, M.M.; Lerner, M.M.; Visco, S.J.; De Jonghe, L.C.; Electrochem. Soc. 1992, 139, 2077.

9. Ue, M.; Visco, S.J.; De Jonghe, L.C.; Denki Kagaku oyobi Kogyo Butsuri Kagaku 1993, 61, 1409 (CA: 120:111628b).

10. Visco, S.J.; Liu, M.; Doeff, M.M.; Ma, Y.P.; Lampert, C.; De Jonghe, L.C.; Solid State Ionics 1993, 60, 175.

11. Ma, Y.; Doeff, M.M.; Visco, S.J.; De Jonghe, L.C.; J. Electrochem. Soc. 1993, 140, 2726.

12. Sotomura, T.; Uemachi, H.; Naoi, K.; Oyama, N.; Electrochim. Acta 1992, 37, 1851.

13. Naoi, K.; Menda M.; Ooike, H.; Oyama, N.; Electroanal. Chem. 1991, 318, 395 .

14. Sotomura, T.; Uemachi, H.; Miyamoto, Y.; Kaminaga, H.; Oyama, N.; Denki Kagaku oyobi Kogyo Butsuri Kagaku 1993, 63, 1366 (CA: 120: 81488m).
15. Oyama, N.; Tatsuma, T.; Sato, T.; Sotomura, T.; Nature 1995, 373, 598.

16. Sotomura, T.; Tatsuma, T.; Oyama, N.; J. Electrochem. Soc. 1996, 143, 3152.

17. Oyama, N.; Pope, J.M.; Sotomura, T.; J. Electrochem. Soc. 1997, 144, L47.

18. Matsumoto, F.; Ozaki, M.; Inatomi, Y.; Paulson, S.C.; Oyama, N.; Langmuir 1999, 15, 857.

19. Canobre, S.C.; Mendes, C.H.; Del Rio, R.; Biaggio, S.R.; Proceedings of the XI Electroanalytical and Electrochemical Brazilian Symposium, Maragogi, Brazil, 1999.

20. Canobre, S.C.; Biaggio, S.R.; Proceedings of the XIV Congress of the Iberoamerican Society of Electrochemistry, Oaxaca, Mexico, 2000.

21. Andrade, G.T.; Aguirre, M.J.; Biaggio S.R.; Electrochim. Acta 1998, 44, 633.

22. Pouget, J.P.; Hsu, C.H.; MacDiarmid, A.G., Synth. Met. 1992, $51,95$.

23. Oyama, N.; Pope, J.M.; Tatsuma, T.; Hatozaki, O.; Matsumoto, F.; Chi, Q.J.; Paulson, S.C.; Iwaku, M.; Macromol. Symp. 1998, $131,103$.

24. Shouji, E.; Yokoyama, Y.; Pope, J.M.; Oyama, N.; Buttry, D.A.; J. Phys. Chem. B 1997, 101, 2864.

25. Killian, J.G.; Coffey, B.M.; Gao, F.; Poehler, T.O.; Searson, P.C.; J. Electrochem. Soc. 1996, 143, 936.

Received: February 3, 2003

Published on the web: August 14, 2003

FAPESP helped in meeting the publication costs of this article. 